\title{
CONSIDERATIONS ON THE USE OF SENTINEL-1 DATA IN FLOOD MAPPING IN URBAN AREAS: ANKARA (TURKEY) 2018 FLOODS
}

\author{
Beste Tavus ${ }^{1}$, Sultan Kocaman ${ }^{1, *}$, Candan Gokceoglu², Hakan A. Nefeslioglu ${ }^{2}$ \\ ${ }^{1}$ Hacettepe University, Department of Geomatics Engineering, Ankara, Turkey - sukocaman@ gmail.com \\ ${ }^{2}$ Hacettepe University, Department of Geological Engineering, Ankara, Turkey
}

SS: Commission V, SS: Atmosphere, Ocean, Weather and Climate

KEY WORDS: Flood Mapping, Hazard, Risk, Sentinel 1, Ankara (Turkey)

\begin{abstract}
:
Flood events frequently occur due to -most probably- climate change on our planet in the recent years. Rapid urbanization also causes imperfections in city planning, such as insufficient considerations of the environmental factors and the lack of proper infrastructure development. Mapping of inundation level following a flood event is thus important in evaluation of flood models and flood hazard and risk analyzes. This task can be harder in urban areas, where the effect of the disaster can be more severe and even cause loss of lives.

With the increased temporal and spatial availability of SAR (Synthetic Aperture Radar) data, several flood detection applications appear in the literature although their use in urban areas so far relatively limited. In this study, one flood event occurred in Ankara, Turkey, in May 2018 has been mapped using Sentinel-1 SAR data. The preprocessing of Sentinel-1 data and the mapping procedure have been described in detail and the results have been evaluated and discussed accordingly. The results of this study show that SAR sensors provide fast and accurate data during the flooding using appropriate methods, and due to the nature of the flood events, i.e. heavy cloud coverage, it is currently irreplaceable by optical remote sensing techniques.
\end{abstract}

\section{INTRODUCTION}

Flooding has been frequently observed recently throughout the world and most of the flooding events occur in a destructive manner. They harm urban infrastructure, agricultural land, and even cause loss of lives. Therefore, it is very important to know the land surface characteristics in case of floods. As with all natural disasters, it is necessary to know the spatial and temporal distributions of the data in order to take successful measures in flood disaster.

The advancements in remote sensing methods coupled with new sensor technologies and launch of Earth Observation (EO) satellites have been increasingly improving the mapping methods from space also under difficult circumstances, such as thick clouds, rugged terrain or other inflexible geographical or meteorological conditions. Both optical and microwave sensors are important data providers for flood mapping and monitoring. Optical sensors are affected by the cloud cover and cannot supply useful data at night either. The flood events occur under heavy cloud coverage, which limits the use of optical sensors in this area significantly. The temporal and spatial availability of SAR (Synthetic Aperture Radar) data has been increasing, and flood detection is candidate to be a very popular application area of SAR data.

SAR can penetrate the cloud cover and capture images day or night, which is particularly useful for monitoring flood disaster (Psomiadis, 2016). The first methods and algorithms used to detect floods with SAR were introduced in the early 1980s and have been developed since then (Lowry et al., 1981). Thanks to the advantages of SAR data, it has become widely used in flood extent and magnitude mapping in recent years. Various methods have been used within the literature to detect water from SAR data. These include histogram thresholding (manual and automated), fuzzy classification, automatic segmentation, region growing, texture analysis and change detection (Zhang et al. 2018). Presently, the most common approach for using EO data for flood mapping is based on SAR images.

Sentinel-1 is a SAR mission of the Copernicus Program of European Space Agency (ESA). The contribution of Sentinel-1 to the application of flood mapping arises from the sensitivity of the backscatter signal to open water (Henry et al., 2006).

Ankara is the capital city of Turkey with second largest population (ca. $5.5 \mathrm{~m}$ inhabitants) after Istanbul (TUIK, 2017). Several flooding events have been encountered in Ankara in recent years and the frequency of occurrence is also increasing. Although occurrence frequency of these events are directly linked with climate change; the fact that they also turn into disasters pretty quickly are related to; i) the difficulties in proper site selection under the circumstances of rapid urbanization, ii) the increasing needs of modern living; and iii) insufficiency and inefficient use of the infrastructure. In order to predict hazards and improve disaster mitigation, novel technologies should be exploited and new methodologies for their use should be developed.

The main aim of this study is to map a significant flood event, which took place in May $5^{\text {th }}, 2018$, in Ankara using Sentinel-1 data. For this purpose, the study has been carried out in four main stages; i) representation of the general characteristics of the flood event, ii) pre-processing of Sentinel 1 data, iii) mapping procedure, and iv) evaluation of the results and discussion.

The study area and the flood event is described in the following section. Pre-, during/post-event Sentinel-1 datasets have been downloaded from the Copernicus Open Access Hub of ESA

\footnotetext{
* Corresponding author
} 
(2018) and processed using the SNAP Tool (SNAP, 2018) for radiometric calibration, thermal noise removal, speckle filtering and geometric correction. Flood maps are produced by using a combination of methods proposed by Twele et al. (2016) and Zhang et al. (2018). The possibilities and the limitations in implementation of Sentinel 1 data in mapping of urban floods have been evaluated and discussed accordingly.

\section{MATERIALS AND METHODS}

\subsection{Study Site and the Flood Event}

The selected study site is the capital city of Turkey, Ankara, which is located in central Anatolia. Figure 1 shows the location and the extent of the study area $\left(\sim 2.800 \mathrm{~km}^{2}\right)$. The buildings in the city are mostly high, from a few floors to several tenths. Industrial and settlement areas are closely located in the same neighbourhoods, while the amount of agricultural and open areas are almost negligible in the city center. Regarding the topography, the elevation range in the city extents is between 780 $\mathrm{m}$ to $1300 \mathrm{~m}$. For the whole study area, the maximum elevation from mean sea level is ca. $1800 \mathrm{~m}$.

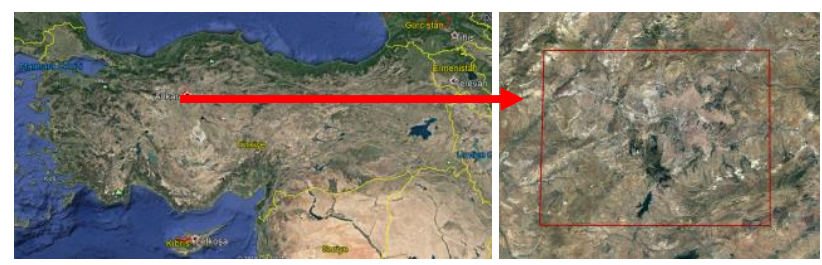

Figure 1. Location of the study area (image credit: Google Earth).

The flood event occurred in Ankara on May $5^{\text {th }}, 2018$, has caused damages in infrastructure, houses and offices, and also caused the injury of 6 persons (Figure 2). Two other similar events have occurred just after this one (May 20 and June 212018 ).
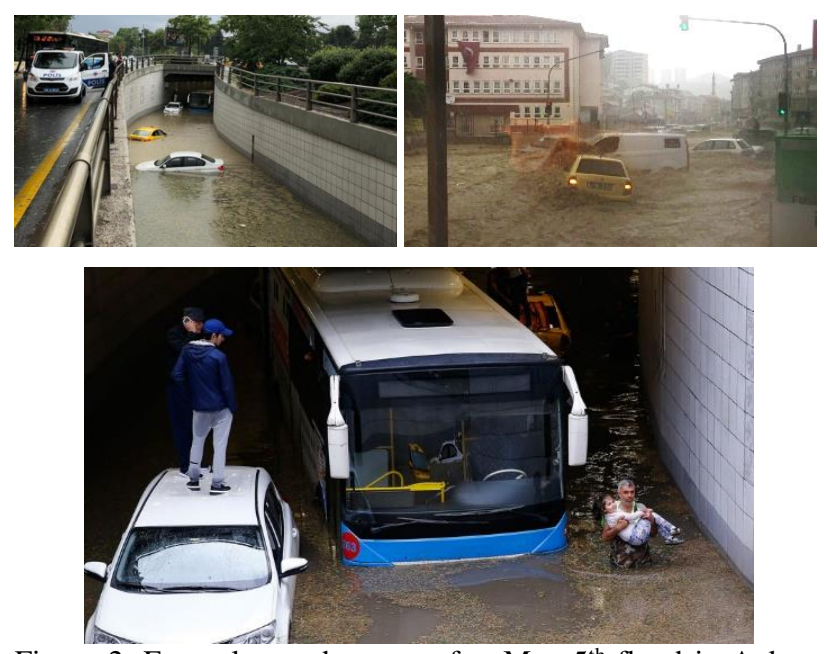

Figure 2. Examples to damages after May $5^{\text {th }}$ flood in Ankara (photo credits: http://www.cumhuriyet.com.tr, www.ntv.com.tr, www.aa.com.tr - accessed on September $25^{\text {th }}, 2018$ ).

\subsection{Sentinel-1 Datasets}

Sentinel-1 SAR data in C-band sensor have been used in this study. Sentinel-1 satellite constellation consists of Sentinel-1A and Sentinel-1B, each of them carrying one two radar sensor and both of them operating in the same orbit. Sentinel-1A and Sentinel-1B were launched by the ESA on April 3, 2014 and April 25, 2016, respectively (Plank, 2014). The revisit time of each satellite (Sentinel-1A and Sentinel-1B) is 12 days, which means 6 days for the combined constellation (Nagler et al. 2016) and can be considered as a high visiting time. The data obtained from the Sentinel-1 sensors have 4 different modes with different resolutions, extents, polarizations and incidence angles: Stripmap (SM), Interferometric Wide Area (IW), Extra Wide (EW) and Wave (Cazals et al. 2016).

In this study, three Sentinel-1 SAR images collected at the IW area mode have been used. This mode is the main acquisition mode over land and has single and dual polarizations (VV: vertical transmitting- vertical receiving; and $\mathrm{VH}$ : vertical transmitting- horizontal receiving) (Cazals et al. 2016). Data obtained under one wet (DS-1) and two dry (DS-2, DS-3) weather conditions have been selected for the investigations. The Sentinel-1 images used here have been provided freely from the Scientific ESA Data Center website (https://scihub.copernicus.eu/dhus/\#/home). The Sentinel-1 images have been delivered in Ground Range Detected (GRD) format with an original spatial resolution of $20 \times 22 \mathrm{~m}$ for range and azimuth, and all of them were acquired on descending pass direction. The GRD data have been resampled to a ground pixel size 10 × $10 \mathrm{~m}$ (Torres et al. 2012).

The main characteristics (i.e. dataset ID, acquisition date, data format and mode, acquisition model, weather conditions and aim of use in this study) of the SAR datasets used in the study are given in Table 1. As summarized in the table, the first dataset (DS-1) is acquired right after the flood. The heavy rainfall occurred between 15:00-17:00 (given in GMT+3, standard time zone of Turkey) in the afternoon. The SAR dataset (DS-1) was acquired on 18:42 (GMT+3). The second and third datasets (DS2 and DS-3) have been used to create reference data for non-flood situation of the city in terms of topography and land cover. The last one, DS-4, has been acquired two months after the flood and used to generate a land cover map of the area to have an initial overview and impression.

\begin{tabular}{|l|c|c|c|c|}
\hline ID & $\begin{array}{c}\text { Acquisiton } \\
\text { date }\end{array}$ & $\begin{array}{c}\text { Data format } \\
\text { and mode }\end{array}$ & $\begin{array}{c}\text { Acquisition } \\
\text { model }\end{array}$ & Weather \\
\hline DS-1 & $05 / 05 / 18$ & GRD-IW & VV + VH & Wet \\
DS-2 & $26 / 08 / 17$ & GRD-IW & VV + VH & Dry \\
DS-3 & $21 / 07 / 17$ & GRD-IW & VV + VH & Dry \\
DS-4 & $04 / 07 / 18$ & GRD-IW & VV + VH & Dry \\
\hline Usage and download URLs: \\
DS-1: acquired after flood \\
https://scihub.copernicus.eu/dhus/odata/v1/Products('a9fc45 \\
6d-97f2-4c35-b4ff-fc14f60d4202')/\$value \\
DS-2: used to create reference data \\
https://scihub.copernicus.eu/dhus/odata/v1/Products('ebe985 \\
fe-72a1-42fb-8df7-cb11f2954e13')/\$value \\
DS-3: used to create reference data \\
https://scihub.copernicus.eu/dhus/odata/v1/Products('f75d4d \\
e0-c6a7-469a-a921-49a818c3575a')/\$value \\
DS-4: used to create land cover map \\
https://scihub.copernicus.eu/dhus/odata/v1/Products('dbfb17 \\
4f-e106-4733-b1dd-0d554e28041d')/\$value \\
\hline
\end{tabular}

Table 1. The base information of used Sentinel-1 scenes.

\subsection{SAR Pre-processing and the Overall Workflow}

SAR polarizations is an essential factor in flood detection (Psomiadis, 2016). VV polarized images are considered more 
adequate for flood and water bodies detection than $\mathrm{VH}$ in several previous studies (Twele et al. 2016; Henry et al. 2006; Brisco et al. 2008; Manjusree et al. 2012; Clement at al. 2017). For this reason, VV polarized images have been used in this study. An overall workflow of the methodology used here is provided in Figure 3.

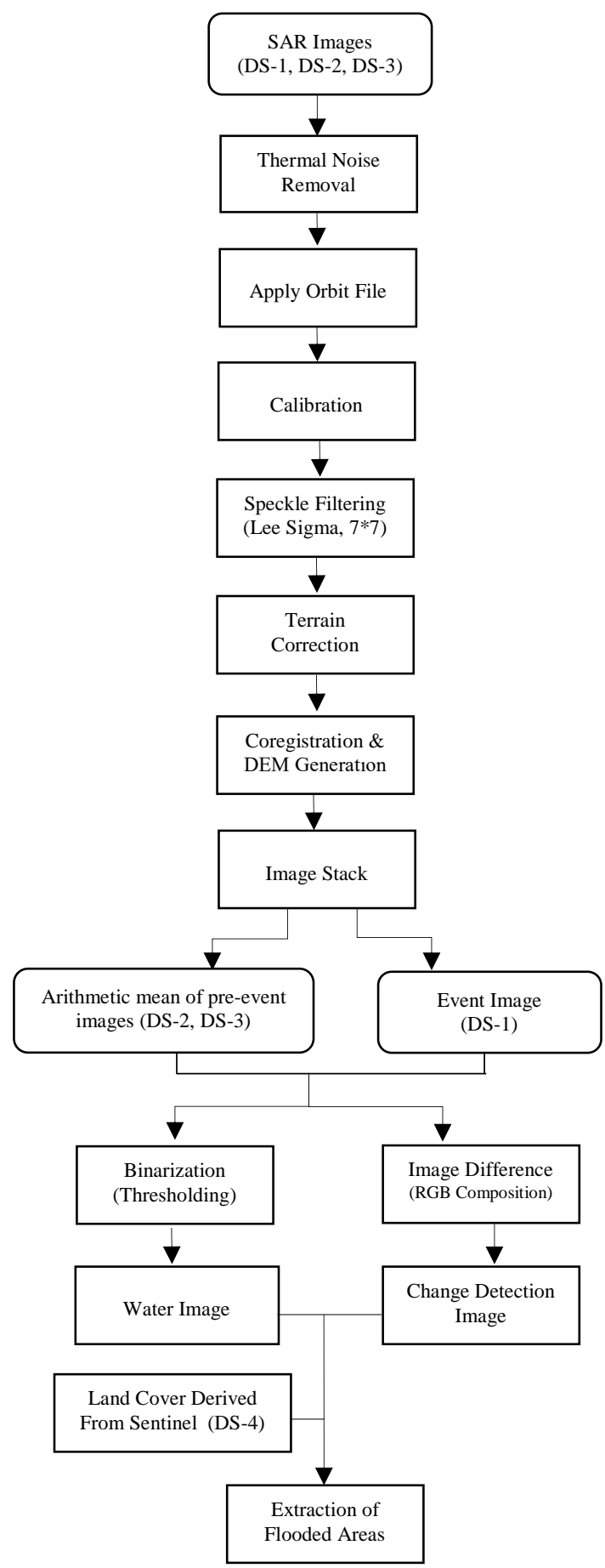

Figure 3. Flowchart of the methodology.

Thermal noise affects the quality of the images, especially in low backscatter areas like calm seas and lakes. Therefore, thermal noise was removed in this step using the SNAP Toolbox.

Precise orbit file was applied, because the orbit file provides accurate satellite position and velocity information. (SNAP
Help). Calibration is an important step for SAR imagery process. Calibration is required for quantitative analysis of SAR images obtained from different sensors or at different times from the same sensor. Therefore, image calibration has been applied so that the pixel values of the images could directly represent radar backscatter and $\sigma_{0}$ bands were created.

One of problems faced with SAR imagery is speckle noise caused by the random effects from the multiple backscatters that occur within each resolution cell (Singh and Shree, 2017). Speckle noise is a form of noise which reduces the quality of an image and may make visual or digital interpretation more difficult, so it is generally desirable to reduce before interpretation and analysis (Miranda and Meadows, 2015).

In order to reduce the speckle noise in SAR images, several adaptive filters (i.e. boxcar, Frost, Mean, Median, Lee, Refined Lee, Lee Sigma and Gamma-MAP) were developed in SNAP toolbox. At this step, single product speckle filter method based on Lee Sigma has been used to remove the speckle noise, as Lee and Lee Sigma filters have been found to be useful in many studies (Lee and Pottier, 2009; Jaybhay and Shastri, 2015). Lee Sigma filter utilize the statistical distribution of the DN (digital number) values within the moving kernel to estimate the value of the pixel of interest and make smoothing in the low variance areas but not in high variance areas. In order to determine the optimal filter size, both images (VH and VV) were applied with a $3 \times 3,5 \times 5$, and $7 \times 7$ filter size Lee Sigma filter. Examples to unfiltered and filtered images from the May $5^{\text {th }}$ dataset are given in Figure 4. When the effect of the applied filter on homogeneous surfaces (e.g. lake surfaces) is checked, it can be seen that $7 \times 7$ filter size performs better than other two filters with smaller sizes.

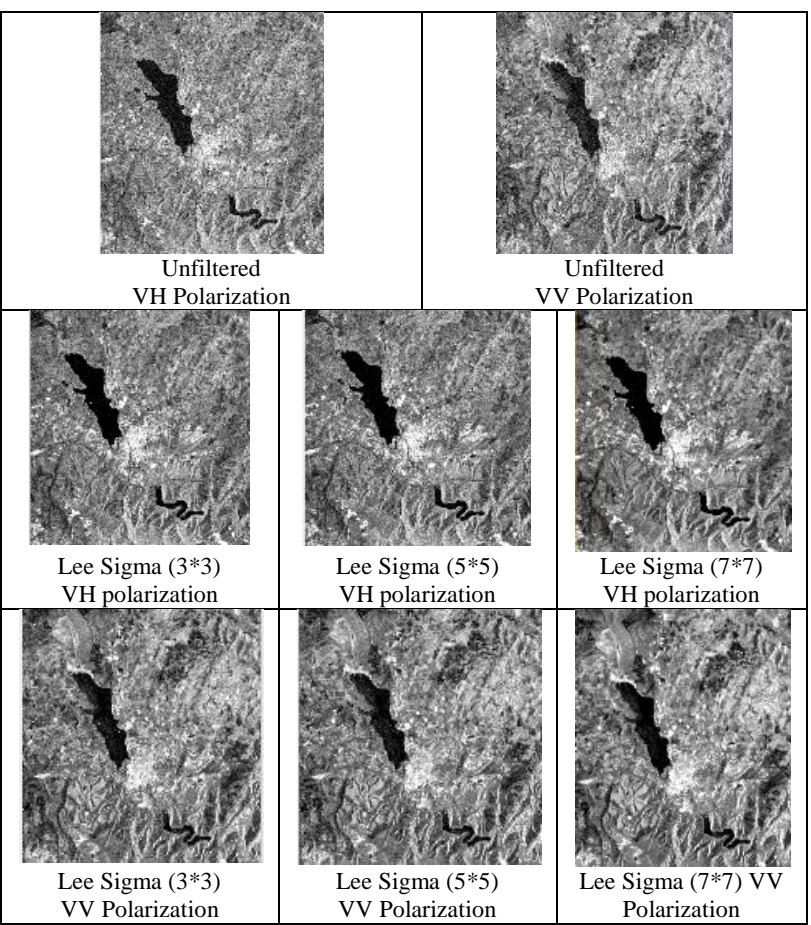

Figure 4. Unfiltered VV and VH polarized images and application results of different filter sizes (a part of May $5^{\text {th }}$, 2018 Sentinel-1 image).

Due to topographic variations and the viewing angle of the satellite sensor, SAR images may be distorted. Terrain corrections have been performed to compensate these distortions 
so that the geometric representation of the image will be as close as possible to the real world (O'Grady et al. 2013). For this purpose, the images have been terrain-corrected and orthorectified using the Range Doppler Terrain Correction algorithm. SRTM-3Sec (Auto Download) has been used as the digital elevation model (DEM) in SNAP Toolbox.

Since the SAR datasets have differences in the sensor, acquisition time, and viewing angle; a coregistration step has been applied to remove the geometric differences. Image stacking has been applied for further analysis, thresholding and RGB composition for mapping.

\subsection{The Mapping Procedure}

After the completion of SAR pre-processing steps, the produced images have been pre-processed prior to the final flood-map generation (Figure 3). Several specific sub-areas have been selected for the analysis and named as region of interest (ROI): Mogan Lake (ROI-1); Eymir Lake (ROI-2); Bayindir Dam (ROI3); Etimesgut Airport (ROI-4); Bogazici Neighbourhood (ROI5) in Mamak District, a part of the city where was effected most from this flooding; and Ankara Cayi (ROI-5), which is a river turned into an open canal.

Two methods have been applied to pre-process the SAR images and thus enhance them for further processing: (i) binarization by selecting two threshold values for the detection of water areas, and (ii) taking image differences (between pre- and during-event images). The threshold values have been determined from the analysis of pre-event datasets (mean of DS-2 and DS-3 images). The arithmetic difference between the thresholded image of DS1 and mean image produced at the previous step have been computed to determine the change areas.

The thresholding method (histogram thresholding) is a simple but widely used and effective method to generate binary images (Pulvirenti et al. 2011; Schumann, et al. 2009). Here, the thresholding method is used for delineating water from nonwater. For this, the histogram of the filtered back-scattering coefficient showing the Mogan Lake and its surroundings (ROI1) has been analysed. There are multiple peak values in the histogram. Low values of the backscatter histogram correspond to the water, and high values correspond to the non-water class (Figure 5).

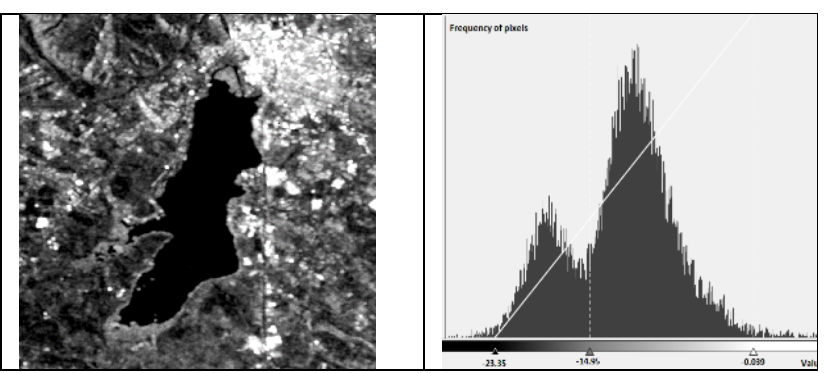

Figure 5. Mogan Lake surroundings and histograms of arithmetic mean of pre-event images.

As a result of the visual investigations of arithmetic mean of preevent images, the pixel values of the water areas have been determined to be between -26 and $-17.5 \mathrm{~dB}$. The threshold values obtained from the arithmetic backscatter histogram have been applied to both images (arithmetic mean of pre-event images and event image) using logical operators for binarize the images and results from ROI-1 are provided in Figure 6.

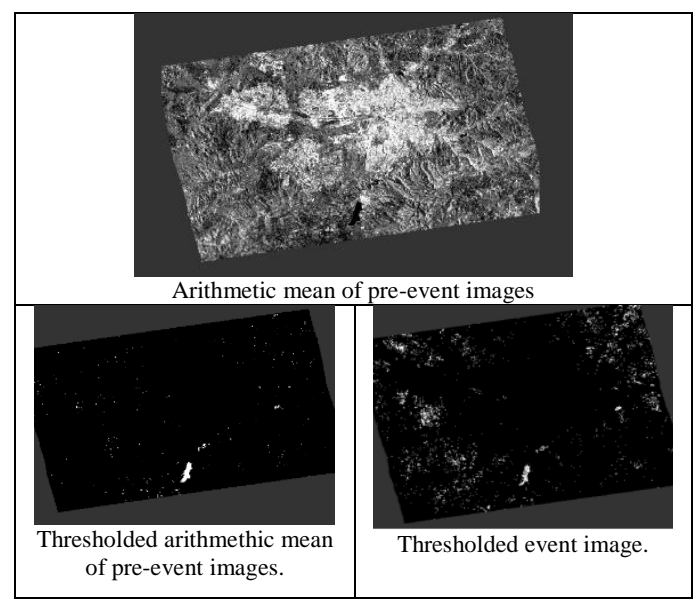

Figure 6. Mogan Lake (ROI-1) surroundings and histograms.

In the second stage of image pre-processing, the difference between the arithmetic mean of the two pre-event images and the event image has been taken and the resulting difference image is used for change analysis. The difference image mainly indicates a change in back scattering values over time.

The land cover map of the region has been generated from DS-4 for visual evaluation of the regions. Hierarchical decision trees are commonly used for land cover mapping but usually require an interpretation by the observer. To avoid this situation, classification methods that originate from machine learning have been increasingly prominent in the literature (Balzter et al. 2015). One of these methods is random forests by Breiman (2001). Random forests, a machine learning supervised classifier, often provide better land cover classification accuracies than for example the maximum likelihood approach (Balzter et al. 2015; Waske and Brown 2009; Van Beijma et al. 2014). In this study, the land cover map has been produced in SNAP software using random forest method and the DS-4 acquired on July 4, 2018 (Figure 7). Five basic types of classes have been determined, i.e. water, urban, forest, agriculture and bare land. The classifier has been trained by selecting representative areas (polygons) for each class. Since the visual interpretation of the SAR images is difficult due to the texture, satellite images on Google Earth have been used as aid for selecting the most suitable areas. From visual checks on the land cover maps, it is seen that shadows in the dataset cannot be separated from water areas with this classification approach. Further investigations in this field will be performed in the future.

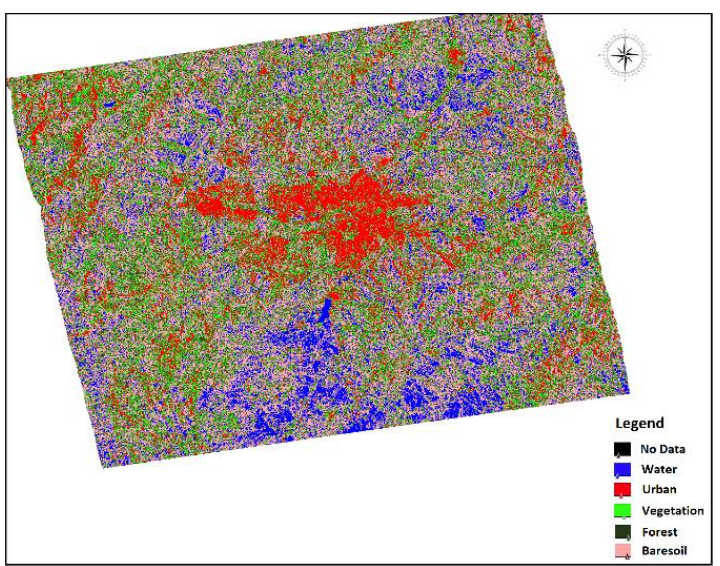

Figure 7. Land cover map derived from Sentinel (generated from DS-4). 


\section{RESULTS AND DISCUSSIONS}

Since urban areas consist of a large number of concrete, steel and corners that act as strong scatterers, it is difficult to detect floods using SAR data in these areas. In addition, the spatial resolution $(10 \times 10 \mathrm{~m})$ is not the most suitable for separating buildings, streets, etc. Some challenges have been encountered in determining the flood areas using SAR in this study. These situations are the radar shadow, smooth surfaces, and steep incidence angle. Radar shadow can confuse flooded areas, because shadow areas yield no backscatter as they do on smooth water surfaces.

The resulting flood map of the whole study area is given in Figure 8. Detailed (zoomed) images of selected ROIs are given in Figure 9. RGB combination involving the arithmetic mean of pre-event intensity images $(R)$, event image $(G$ and $B)$ in the VV polarization are given on the right side of the Figure 9. The red areas in the RGB images in Figures 8 and 9 represent bare soil which are flooded in VV polarization; the gray tones represent the areas where there is no change between two images. The blue color areas represent higher response surfaces for the flood date, and do not relate to the flooding directly.

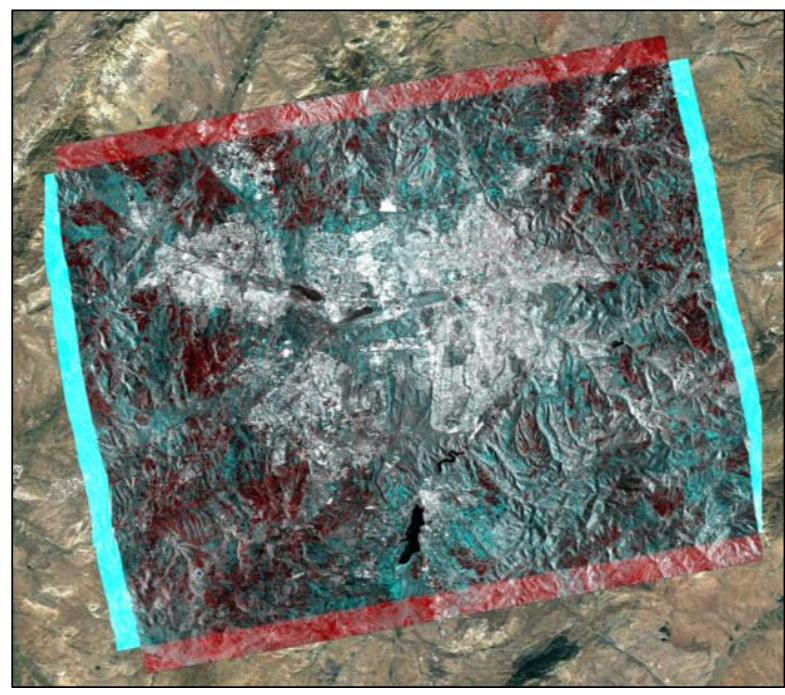

Figure 8. RGB composition of study area.

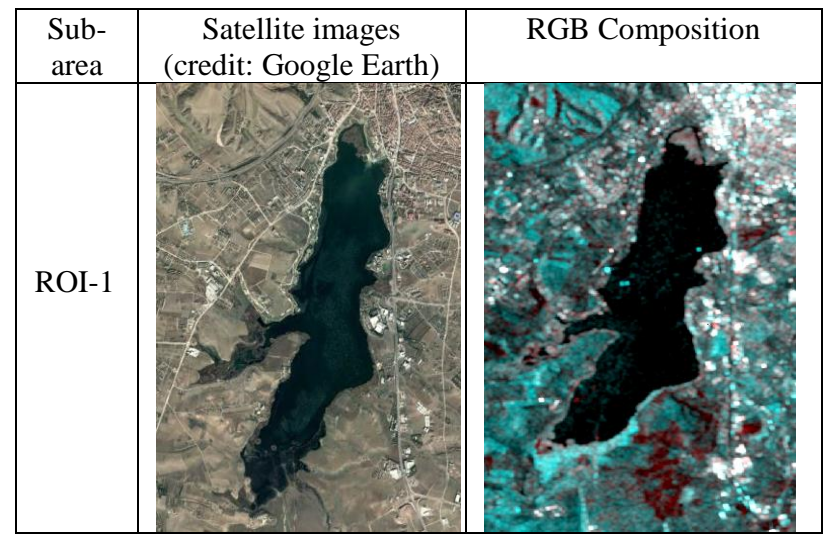

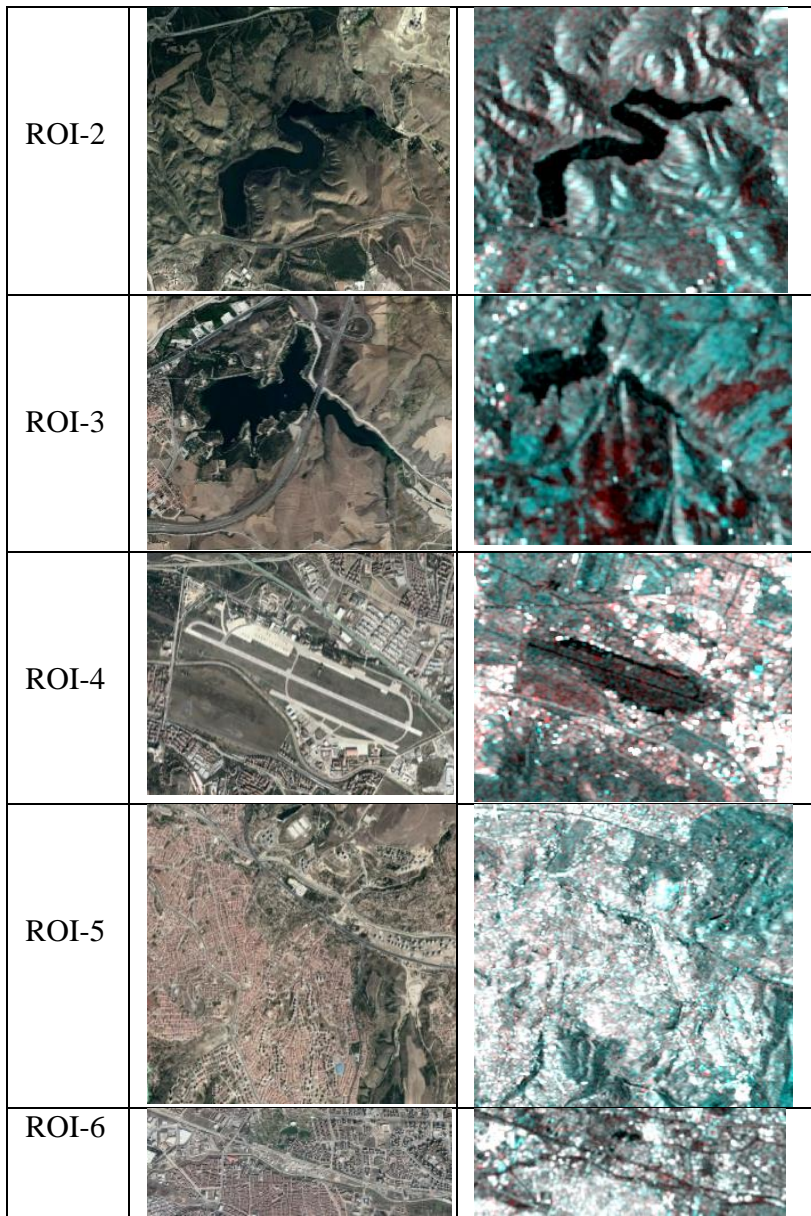

Figure 9. RGB maps produced from the Sentinel-1 data obtained right after the flood on May 5, 2018, in Ankara (right). Optical satellite images (credit: Google Earth) for the same ROIs (left). Light red (pink) and black areas denote water. The darker red is mostly seen on rugged topography and denote shadows.

\section{CONCLUSIONS AND FUTURE WORK}

Instant mapping of flash floods would help disaster mitigation efforts and assess the post-disaster damages. Although processing of SAR data is still an expert task, development of standardized procedures and guidelines would help non-experts to utilizing these data more efficiently. The valuable efforts of ESA on the provision of free data (e.g. Sentinel-1 and Sentinel2) and software (e.g. SNAP) is considered as extremely important in this sense.

The preliminary results of the present study show that Sentinel-1 data can be used in urban flood mapping although the temporal resolution (i.e. revisit time) of the satellite bring the major limitation and the detection of the inundation level is more reliable especially around surface water bodies due to low spatial resolution of the images.

The future work of this study include exploitation of other floods occurred in 2018 using Sentinel-1 data and comparison with predictions (e.g. flood susceptibility maps). In addition, the topographic wetness index (TWI) will be used for verification of the results by identifying the accumulation areas. 
The shadows and water cannot be separated reliably and also the generation of land cover maps is affected from this situation. Further investigations on these topics will be performed in the future. In addition, methods for automatic extraction of the flooded areas should be implemented in the future.

\section{ACKNOWLEDGEMENTS}

The authors gratefully acknowledge Batuhan Osmanoglu for reviewing the overall workflow.

\section{REFERENCES}

Balzter, H., Cole, B., Thiel, C., and Schmullius, C., 2015. Mapping CORINE Land Cover from Sentinel-1A SAR and SRTM Digital Elevation Model Data using Random Forests. Remote Sensing, Vol.7, pp. 14876-14898.

Breiman, L., 2001. Random forests. Machine Learning, 45, pp. 5-32.

Brisco, B., Touzi, R., Van der Sanden, J.J,, Charbonneau, F., Pultz, T.J., D’lorio, M., 2008. Water resource applications with RADARSAT-2 a preview. Journal International Journal of Digital Earth, Vol. 1, pp.130-147. https://doi.org/10.1080/17538940701782577.

Cazals, C., Rapinel, S., Frison, P.L., Bonis, A., Mercier, G., Mallet, C., Corgne, S., Rudant, J.P., 2016. Mapping and characterization of hydrological dynamics in a coastal marsh using high temporal resolution Sentinel-1A images. Remote Sensing 8(7):570 DOI 10.3390/rs8070570.

Clement, M.A., Kilsb, G., Moore, P., 2017. Multi-temporal synthetic aperture radar flood mapping using change detection. Journal of Flood Risk Management. 39, 130, pp. 152-168 https://doi.org/10.1111/jfr3.12303.

ESA Scientific Data Hub - Copernicus, 2018. Available online: https://www.scihub.copernicus.eu/dhus/\#/home/ (1 September 2018).

Henry, J.B., Chastanet, B., Fellah, K., Desnos, Y.L., 2006). Envisat multi-polarized ASAR data for flood mapping. International Journal of Remote Sensing, 27(10), pp. 1921-1929, https://doi.org/10.1080/01431160500486724.

Jaybhay, J., Shastri, R., 2015. A study of speckle noise reduction Filters. Signal \& Image Processing: An International Journal (SIPIJ), Vol 6, No 3.

Lee, J.S., Pottier, E., 2009. Polarimetric Radar Imaging: From basics to applications. In Optical Science and Engineering; CRC Press: Boca Raton, FL, USA, Volume 142.

Lowry, R.T., Langham, E.J., Murdy, N., 1981. A preliminary analysis of SAR mapping of Manitoba flood. Proc. Satellite Hydrology, Fifth Anniversary William T. Pecora, Memorial Symposium on Remote Sensing American, Water Resource Association Technical Publication, 81-1, pp. 316-323.

Manjusree, R., Kumar, L.P., Bhatt, C.M., Rao, G.S., Bhanumurthy. V., 2012. Optimization of threshold ranges for rapid flood inundation mapping by evaluating backscatter profiles of high incidence angle SAR images. International Journal of Disaster Risk Science, Vol 3, No 2, pp. 113-122. https://doi.org/10.1007/s13753-012-0011-5.
Miranda, N., Meadows, P.J., 2015. Radiometric Calibration of S1 Level-1 Products Generated by the S-1 IPF, ESA-EOPGCSCOP-TN-0002; European Space Agency: Paris, France.

Nagler, T., Rott, H., Ripper, E., Bippus, G., Hetzenecker, M., 2016. Advancements for snowmelt monitoring by means of sentinel-1 SAR. Remote Sensing, Vol 8, No 4, DOI 10.3390/rs8040348.

O'Grady, D., Leblanc, M., Gillieson, D., 2013. Relationship of local incidence angle with satellite radar backscatter for different surface conditions. International Journal of Applied Earth Observation and Geoinformation, Vol 24, pp. 42-53, https://doi.org/10.1016/j.jag.2013.02.005.

Plank, S., 2014. Rapid damage assessment by means of multitemporal SAR- A comprehensive review and outlook to Sentinel1. Remote Sensing, Vol 6, pp. 4870-4906, https://doi.org/10.3390/rs6064870.

Psomiadis, E., 2016. Flash flood area mapping utilizing Sentinel1 radar data. In Proceedings of the Earth Resources and Environmental Remote Sensing/GIS Applications VII, Edinburgh, UK, 26-29 September; doi:10.1117/12.2241055.

Pulvirenti, L., Chini, M., Pierdicca, N., Guerriero, L., Ferrazzoli, P., 2011. Flood monitoring using multitemporal COSMOSkyMed data: image segmentation and signature interpretation. Remote Sensing Environment, Volume 115, Issue 4, pp. 9901002, https://doi.org/10.1016/j.rse.2010.12.002.

Schumann, G., Di Baldassarre, G., Bates, P.D., 2009. The utility of spaceborne radar to render flood inundation maps based on multialgorithm ensembles. IEEE Transactions on Geoscience and Remote Sensing, Volume 47, Issue 8, pp. 2801-2807, DOI 10.1109/tgrs.2009.2017937.

Singh, P., Shree, R., 2016. Analysis and effects of speckle noise in SAR images. In Advances in Computing, Communication, \& Automation (Fall), ICACCA 2016, pp. 2-6, DOI 10.1109/ICACCAF.2016.7748978.

SNAP, 2018. Sentinel Application Platform. http://step.esa.int/main/toolboxes/snap/ (1 September 2018).

Torres, R., Snoeij, P., Geudtner, D., Bibby, D., Davidson, M., Attema, E., Potin, P., Rommen, B., Floury, N., Brown, M., 2012. GMES Sentinel-1 mission. Remote Sensing of Environment, Volume 120, pp.9-24, https://doi.org/10.1016/j.rse.2011.05.028.

Twele, A., Cao, W.X., Plank, S., Martinis, S., 2016. Sentinel-1based flood mapping: a fully automated processing chain. International Journal of Remote Sensing, Volume 37, Issue 13, pp.2990-3004,https://doi.org/10.1080/01431161.2016.1192304.

TUIK, 2017. Turkish Statistical Institute Report on Population of Cities. http://tuik.gov.tr/PreTablo.do?alt_id=1059 (1 September 2018).

Van Beijma, S., Comber, A., Lamb, A., 2014. Random forest classification of salt marsh vegetation habitats using quadpolarimetric airborne SAR, elevation and optical RS data. Remote Sensing Environent, Volume 149, pp. 118-129, https://doi.org/10.1016/j.rse.2014.04.010. 
The International Archives of the Photogrammetry, Remote Sensing and Spatial Information Sciences, Volume XLII-5, 2018 ISPRS TC V Mid-term Symposium "Geospatial Technology - Pixel to People", 20-23 November 2018, Dehradun, India

Zhang, B., Wdowinski, S., Oliver-Cabrera, T., Koirala, R., Jo, M.J., Osmanoglu, B., 2018. Mapping the Extent and Magnitude of Sever Flooding Induced by Hurricane IRMA with MultiTemporal SENTINEL-1 SAR and Insar Observations. ISPRSInternational Archives of the Photogrammetry, Remote Sensing and Spatial Information Sciences, pp. 2237-2244, https://doi.org/10.5194/isprs-archives-XLII-3-2237-2018.

Waske, B., Braun, M., 2009. Classifier ensembles for land cover mapping using multitemporal SAR imagery. ISPRS Journal of Photogrammetric Remote Sensing, Volume 64, Issue 4, pp. 450457, https://doi.org/10.1016/j.isprsjprs.2009.01.003. 